\title{
UMA ANÁLISE DE NARRATIVA DO "CASO SCHREBER" À LUZ DO NOVO HISTORICISMO: NEGOCIAÇÕES FREUDIANAS
}

Rogério Paes Henriques

Doutor em Saúde Coletiva do Instituto de Medicina Social (IMS) da

Universidade do Estado do Rio de Janeiro (Uerj). Psicólogo; psicanalista; professor universitário.
RESUMO: Nesta análise do "caso Schreber" em sua intertextualidade com os escritos de Karl Abraham, sugere-se que o ensaio clínico de Freud foi redigido em um diálogo com o contexto histórico de sua época, refletindo as relações de poder, então vigentes. Pretende-se resgatar a historicidade do texto de Freud sobre Schreber, e para tanto recorre-se às análises críticas do novo historicismo como método de abordagem do texto freudiano. Expõem-se, então, os diferentes níveis de negociações presentes nesse ensaio clínico.

Palavras-chave: Sigmund Freud, caso Schreber, Karl Abraham, novo historicismo.

ABSTRACT: An analysis of the narrative structure of "Schreber's Case" in the light of new historicism: the Freudians negociations. This study of "Schreber's Case" focuses its intertextuality with the articles of Karl Abraham. It has been suggested that the Freud's clinical essay has been written considering the historical context of that period and showing the power relations effective then. The target is to redeem the historical background of Freud's text on Schreber and, for such purpose, critical analysis of the new historicism as a method of approaching the Freudian text has been used. The different levels of negotiations inherent to his clinical essay have been reported.

Keywords: Sigmund Freud, Schreber's Case, Karl Abraham, new historicism.

\footnotetext{
“Fazer justiça a Freud não significa, como muitos temem, sujeitar-se incondicionalmente a um dogma; é bastante possível manter um julgamento independente. (...) Quem pretende ser justo com Freud deve comportar-se segundo as palavras de Erasmo: 'Remove toda pedra, experimenta tudo, não abandones 0 que começaste.." (CARL JUNG. A psicologia da dementia praecox)
}

\section{PRESSUPOSTOS METODOLÓGICOS: O NOVO HISTORICISMO}

Ao justificar, retrospectivamente, a fundação de uma nova escola de crítica literária no fim da década de 1980, nos 
Estados Unidos, Stephen Greenblatt, figura central desse movimento, assim se expressou:

“Alguns anos atrás, com a intenção de sinalizar um afastamento da análise formal e decontextualizada que dominou o new criticism, utilizei o termo 'novo historicismo' para descrever o interesse pelo engaste de objetos culturais nas contingências da história, e o termo conseguiu certa aceitação” (GREENBLATT, 1991, p.245).

Daí nasceu o movimento crítico do novo historicismo, baseando-se nas noções da teoria dos discursos de Michel Foucault e do pensamento desconstrutivista de Jacques Derrida, que veio corroborar para a integração da literatura no âmbito dos signos sociais de modo a restaurar a historicidade do texto e a textualidade da história — na formulação de um dos principais representantes dessa vertente, Louis Montrose.

O novo historicismo procura desvelar como os textos (sejam literários ou não) se situam em meio às práticas discursivas e às instituições de sua época, isto é, como os textos se situam em meio aos contextos. Consiste num modo de interpretação crítica que privilegia as relações de poder como o mais importante contexto para os textos. Como uma prática crítica, ela trata os textos como um espaço no qual as relações de poder ganham visibilidade (BRANNIGAN, 1998, p.6-9). Pretendemos aqui analisar o “caso Schreber” de Freud (1911/1996) desvelando tais relações de poder, isto é, as negociações em jogo que moldaram seu processo de construção, à luz das contribuições dessa vertente literária.

Sugerimos que há, basicamente, três níveis de negociação que se apresentam no texto de Freud sobre Schreber: 1) negociações intrapsicanalíticas, nas quais Freud busca fortalecer sua posição de liderança no interior do movimento psicanalítico, bem como enfraquecer a posição ou expulsar seus discípulos insubordinados; 2) negociações epistemológicas, nas quais o caráter médico da psicanálise é reforçado, associado à sexualidade (teoria da libido); Freud busca afirmar, também, que a psicanálise não é uma fantasia ou um delírio (e que tampouco é uma religião), mas sim que é científica; 3) negociações estilísticas, com a literatura, haja vista o uso de uma linguagem figurativa e o recurso a metáforas literárias.

No intuito de abordar esses diferentes níveis de negociações presentes no caso Schreber de Freud, analisaremos, no próximo tópico, as referências cruzadas entre Freud e Abraham, a partir da intertextualidade do ensaio clínico freudiano com o artigo de Abraham sobre a psicologia da demência precoce (1908/1963). Sugerimos que Freud se mostra apreensivo quanto à sua originalidade no caso Schreber, pois o artigo de Abraham anteciparia boa parte de suas teorizações relativas à psicose de Schreber.

Não sugerimos, com isso, uma pretensa prioridade intelectual de Abraham sobre Freud. Antes de remontarmos às origens da psicanálise das psicoses ele- 
gendo seu verdadeiro fundador e rendendo graças à sua suposta genialidade, pretendemos mostrar as negociações que levaram à construção coletiva da teoria psicanalítica das psicoses, exposta por Freud no caso Schreber. ${ }^{1}$

Como assinala Gallagher \& Greenblatt (2000), a prática crítica do novo historicismo - ao examinar as culturas como textos — permite que "Obras outrora desdenhadas ou ignoradas possam ser tidas por grandes realizações, reivindicando espaço num currículo já atravancado ou diminuindo o valor de trabalhos consagrados numa espécie de mercado de ações literário” (p.20). Desse modo, podem ocorrer remanejamentos entre os textos canônicos e aqueles considerados secundários. Nesse sentido, pretendemos ler o texto de Freud sobre Schreber, cânone por excelência no campo psicanalítico, em sua intertextualidade com o artigo de Abraham sobre a psicologia da demência precoce, considerado 'menor', apontando as complexas correlações entre ambos.

Greenblatt (1991) assinala que a crítica artística em geral, e a literária em particular, deveria se pautar no equilíbrio entre os efeitos de encantamento em que o objeto artístico isolado de seu contexto basta-se a si mesmo, excluindo todo o resto - , e ressonância — que, por outro lado, desperta no expectador ou leitor o sentido da construção cultural e historicamente contingente dos objetos artísticos.

Supomos que o caso Schreber de Freud cause um efeito de encantamento muito maior em seus leitores que de ressonância. Nesse sentido, é comum, ao menos entre os seus comentadores psicanalistas, ${ }^{2}$ o assombro com e a celebração de uma suposta genialidade de Freud, que culmina em certa paralisação e deferência frente o cânone sacralizado. Pretendemos resgatar o efeito de ressonância do texto de Freud sobre Schreber, devolvendo-lhe sua contingência histórica, sem, contudo, negar o incontestável encantamento que ele nos causa; para tanto, analisaremos as relações de poder em jogo na ocasião de sua elaboração, a partir das negociações de Freud com Abraham.

O contexto histórico no qual o caso Schreber foi redigido, no início da década de 1910, pautou-se em intensas disputas de poder no interior do campo psicanalítico, promovidas por psicanalistas dissidentes (sobretudo por Adler e, depois, também por Jung), que questionavam frontalmente os conceitos freudianos fundamentais e ameaçavam a autoridade de Freud na delimitação desse campo,

\footnotetext{
${ }^{1}$ Nesse sentido, Figueiredo assinala: “A psicanálise nos tempos de Freud pode ser um cenário privilegiado para o variado espetáculo da intertextualidade. Freud e seus discípulos ou seus colaboradores ou seus dissidentes hospedam-se, parasitam-se, estraçalham-se uns aos outros e embora haja 'autores' e 'obras' nominais, vão-se formando campos de nexos e rupturas que transcendem uma noção muito estrita de 'obra e de 'autoria'” (FIGUEIREDO, 1999, p.126). ${ }^{2}$ Um panorama detalhado dos comentadores do caso Schreber de Freud nos é fornecido por Lothane (1992, p.343-374).
} 
e, em alguma medida, a própria percepção da coesão do saber psicanalítico, colocando em risco seu intento epistemológico de implantação da psicanálise como ciência. Naquela ocasião, Freud estava envolvido com questões pertinentes à originalidade e influência, isto é, à transferência de conhecimento e autoridade no campo psicanalítico que estava demarcando como seu - empenhava-se em construir como superior sua performatividade retórica nesse campo. ${ }^{3}$

Diante desse contexto adverso de crise de legitimação simbólica nos primórdios da psicanálise, Freud teria assumido em seu ensaio sobre Schreber uma postura defensiva que se refletiria no modo como ele reivindica para si os atributos de uma suposta originalidade no campo das psicoses, a partir de sua série de referências ao texto de Abraham sobre a psicologia da demência precoce.

Por fim, cabe ponderar que a análise crítica proposta neste trabalho com base metodológica no novo historicismo assemelha-se à leitura "próxima e desconstrutiva”, tal como definida por Figueiredo, "que explora as tensões, as trilhas perdidas, as pequenas aberturas do texto que a leitura clássica tende a fechar" (1999, p.19).

Ao menos as leituras empreendidas do caso Schreber de Freud, até então, sobretudo por psicanalistas, têm se mostrado 'sistemáticas' no sentido de expor as 'teses' do texto, isto é, apreender de forma dogmática a visão psicanalítica de Freud acerca da paranóia (criando, assim, a identidade de sentido do texto), seja para endossá-la, ampliá-la, alterá-la, ou, simplesmente, contrariá-la; essas leituras sistemáticas dogmatizantes homogeneízam e esterilizam o texto, recalcando seus elementos heterogêneos, isto é, suprimindo a alteridade textual.

Figueiredo assinala que:

“A leitura próxima desconstrutiva exige a atenção detida no que a leitura sistemática omite, esquece, exclui, expulsa, marginaliza, ignora etc., ou seja, nos elementos deslegitimizados do texto, isto é, os traços diferenciais que permanecem como fundo invisível nas leituras sistemáticas, mas sem os quais nenhuma 'tese' se forma." (FIGUEIREDO, op. cit., p.19)

À luz de nossa leitura 'historicista' e 'próximo-descontrutiva', tomaremos os até então desprezados acréscimos do texto de Freud sobre Schreber, sobretudo suas notas de rodapé, como material privilegiado para nossa análise. ${ }^{4}$ Supomos

\footnotetext{
${ }^{3}$ Vale ressaltar que Freud redigiria $A$ história do movimento psicanalítico (1914/1996), que talvez seja o seu texto mais agressivo, com o intuito de estabelecer claramente os postulados e hipóteses fundamentais da psicanálise, a fim de excluir as concepções de Adler e Jung desse escopo teórico, após o rompimento destes com Freud. Nesse artigo, Freud assume a posição de mestria, delimitando o campo epistemológico da disciplina e desautorizando o discurso de ambos como o de possíveis representantes legítimos da nova 'ciência'.

${ }^{4}$ Justiça seja feita, um autor que me chamou a atenção para a importância desses acréscimos no texto de Freud sobre Schreber foi Santner (1997).
} 
que sejam nessas notas, mais especificamente naquelas referentes a Abraham, que Freud negociou com esse autor, procurando defender sua originalidade intelectual e a integridade de sua voz autoral, isto é, a força performativa de seus enunciados, num contexto de intensa contestação às suas teses psicanalíticas.

\section{UMA ANÁLISE DE NARRATIVA DO CASO SCHREBER À LUZ DAS REFERÊNCIAS CRUZADAS ENTRE S. FREUD E K. ABRAHAM A primeira referência a Karl Abraham no caso Schreber}

Freud faz referência a Abraham pela primeira vez em artigo no início da segunda parte, ocasião na qual apresenta o eixo de sua teoria, demonstrando que a relação entre perseguido e perseguidor, no delírio paranóico, é estabelecida da seguinte maneira:

"O estudo de vários casos de delírios de perseguição levou-me, bem como a outros pesquisadores, à opinião de que a relação entre o paciente e o seu perseguidor pode ser reduzida a fórmula simples [N. de rodapé nota 3: Cf. Abraham, 1908. No decurso desse artigo, o autor, referindo-se a uma correspondência entre nós, escrupulosamente me atribui influência sobre o desenvolvimento de suas opiniões]. Parece que a pessoa a quem o delírio atribui tanto poder e influência, a cujas mãos todos os fios da conspiração convergem, é, se claramente nomeada, idêntica a alguém que desempenhou papel igualmente importante na vida emocional do paciente antes de sua enfermidade, ou facilmente reconhecível como substituto dela. A intensidade da emoção é projetada sob a forma de poder externo, enquanto sua qualidade é transformada no oposto. A pessoa agora odiada e temida, por ser um perseguidor, foi, noutra época, amada e honrada. O principal propósito da perseguição asseverada pelo delírio do paciente é justificar a modificação em sua atitude emocional.” (FREUD, 1911/1996, p.50; grifo nosso)

No início do trecho citado, Freud faz alusão a outros pesquisadores que, junto com ele, teriam estudado "vários casos de delírios de perseguição”, chegando a um denominador comum quanto à relação perseguido-perseguidor. Sugerimos que tal alusão — presença constante no texto freudiano - constituiria uma estratégia narrativa do autor para legitimar-se, uma vez que, como ele havia assumido na introdução do ensaio, sua prática privada de consultório "não é suficiente para levar a quaisquer conclusões analíticas [no que tange às psicoses]" (FREUD, 1911/1996, p.21). Portanto, é necessário receber o aval da experiência clínica de médicos ligados aos hospitais psiquiátricos — locus privilegiado de tratamento dos psicóticos naquela época.

Em seguida, em nota de rodapé, Freud refere-se de modo explícito a Abraham (1908/1963) — que, não por mera coincidência, trabalhou de 1904 a 1907 no famoso Hospital Universitário Burghölzli, de Zurique - , enfatizando o 
'escrúpulo' desse autor em lhe atribuir influência nas idéias expressas em seu artigo de 1908 .

O ‘escrúpulo’ de Abraham, ao qual Freud se refere, aparece em uma nota de rodapé no início de seu artigo de 1908; lá, de fato, Abraham reconhece uma dívida intelectual para com Freud, afirmando:

“Devo agradecer o empreendimento deste trabalho, que vai além das teorias de Freud publicadas até agora [referindo-se aos Três ensaios sobre a teoria da sexualidade, de 1905], às comunicações orais e escritas do próprio prof. Freud; certos aspectos se confirmaram no contato com o prof. Bleuler e com o dr. Jung, no decorrer de meu trabalho na Clínica Psiquiátrica de Zurique.”5 (ABRAHAM, 1908/1963, p.42, nota 3)

Além de 'escrupulosamente' atribuir a Freud influência sobre o desenvolvimento de suas concepções, Abraham ainda diz tê-las confirmado no trabalho institucional desenvolvido junto a dois gigantes da vertente psiquiátrica alemã da época, o prof. Bleuler, e seu promissor discípulo, Jung. Em suma: Abraham reconhece que, se não fossem as teorias da sexualidade de Freud, confirmadas junto àqueles que possuem plena experiência clínica hospitalar para legitimálas no campo psiquiátrico (científico), muito provavelmente não teria escrito o artigo em 1908.

Diante da provável angústia de uma dívida para com Abraham, Freud trata de anulá-la, destacando no texto de Abraham justamente o reconhecimento de uma dívida deste autor para consigo. Essa provável angústia de Freud para com Abraham fica mais visível se levarmos em conta que aquilo que seria descrito por Freud em 1911 como o eixo de sua teoria — a fórmula da relação entre perseguido e perseguidor (citada na íntegra acima) — já havia sido sugerida por Abraham três anos antes:

“Parece que as idéias persecutórias [...] concernem, portanto, às pessoas que anteriormente absorveram a libido transferida do paciente. Em muitos casos, o perseguidor teria sido originalmente o objeto sexual, e o delírio persecutório teria uma origem erógena." (ABRAHAM, 1908/1963, p.48-49)

\section{A segunda referência a Karl Abraham no caso Schreber}

A segunda referência a Abraham no ensaio de Freud (1911/1996, p.73, nota 1) aparece em sua explicação da gênese da megalomania na paranóia. No início da terceira parte de seu texto, uma espécie de prelúdio aos artigos de metapsicologia que escreveria nos anos subseqüentes, Freud expõe as três possíveis construções

\footnotetext{
${ }^{5}$ Esta e as seguintes citações do artigo de Abraham (1908/1963) são traduções nossas.
} 
delirantes do paranóico como defesas ante o desejo homossexual expresso pela proposição inconsciente "Eu (um homem) o amo (outro homem)" — que ele acreditava ser a causa do transtorno em indivíduos do sexo masculino resumidas da seguinte forma: "Os delírios de ciúme contradizem o sujeito, os delírios de perseguição contradizem o predicado, e a erotomania contradiz o objeto" (ibid., p.72). Em seguida, introduz uma outra construção delirante que resulta da contradição de toda a proposição: "Não amo de modo algum — não amo ninguém”, cujo corolário é "Eu só amo a mim mesmo”. Trata-se da megalomania, “(...) que podemos encarar como uma supervalorização sexual do ego e ser assim colocada ao lado da supervalorização do objeto amoroso, com o qual já nos achamos familiarizados" (ibid., p.72-73). No fim deste trecho, Freud insere uma nota de rodapé na qual remete o leitor aos seus Três ensaios sobre a teoria da sexualidade, afirmando a seguir: "A mesma opinião e a mesma formulação serão encontradas nos artigos de autoria de Abraham e Maeder, a que já me referi” (ibid., p.73, nota 1). Quanto a Abraham, Freud refere-se ao seu artigo As diferenças psicossexuais entre a histeria e a demência precoce.

Localizemos no artigo de Abraham o trecho ao qual Freud provavelmente se refere como sendo consoante com suas opiniões expressas no caso Schreber acerca da gênese da megalomania:

"O auto-erotismo da demência precoce é não somente a fonte do delírio persecutório, mas também do delírio de grandeza [megalomania]. Normalmente, duas pessoas que transferiram sua libido reciprocamente estão em uma relação de supervalorização amorosa ("supervalorização sexual" de Freud). O doente mental consagra a si mesmo, enquanto único objeto sexual, toda a libido que o homem normal direciona aos objetos viventes e inanimados de seu entorno. A supervalorização sexual, portanto, só concerne a ele, assumindo enormes proporções; pois ele é seu universo! A supervalorização sexual refletida sobre o eu, ou auto-erótica, é a fonte do delírio de grandeza na demência precoce. Os delírios persecutórios e megalomaníacos estão, portanto, estreitamente relacionados. Todo delírio persecutório na demência precoce contém implicitamente um delírio de grandeza." (ABRAHAM, 1908/1963, p.49, sublinhado nosso, grifo original)

Reparemos que Abraham refere-se a um conceito da teoria da sexualidade freudiana (ver trecho sublinhado acima) para embasar suas idéias expressas nesse artigo de 1908 acerca da demência precoce. Ao fazer referência ao trabalho de Abraham, Freud reforça a importância canônica dos seus Três ensaios, importância essa que já havia sido destacada por ele mesmo ao remeter o leitor prioritariamente ao seu texto, nessa mesma nota de rodapé. 


\title{
A terceira referência a Karl Abraham no caso Schreber
}

A terceira referência a Abraham aparece no texto de Freud no contexto de sua tentativa de explicar como se dá o mecanismo do recalque (Verdrängung) na paranóia de uma perspectiva da economia libidinal, mais ou menos na metade da terceira parte de seu artigo (FREUD, 1911/1996, p.77, nota 2). Nesse momento, ele faz referência outra vez ao artigo de Abraham.

Tentando explicar a gênese de um dos delírios centrais de Schreber no clímax de sua moléstia, referente às suas fantasias escatológicas, isto é, sua convicção de que o mundo (material e humano), tal como ele conhecia, tivera um fim catastrófico, Freud afirma:

\begin{abstract}
“Uma catástrofe mundial deste tipo não é infreqüente durante o estádio agitado em outros casos de paranóia. Se nos basearmos em nossa teoria da catexia libidinal, e seguirmos a sugestão dada pela visão que Schreber tinha das outras pessoas como 'homens apressadamente improvisados', não acharemos difícil explicar estas catástrofes [N. de rodapé nota 2: Cf. Abraham (1908) e Jung (1907). O breve artigo de Abraham contém quase todas as opiniões essenciais apresentadas no presente estudo do caso de Schreber]. O paciente retirou das pessoas de seu ambiente, e do mundo em geral, a catexia libidinal que até então havia dirigido para elas. Assim, tudo tornou-se indiferente e irrelevante para ele, e tem de ser explicado através de uma racionalização secundária, como 'miraculado, apressadamente improvisado'. O fim do mundo é a projeção dessa catástrofe interna; seu mundo subjetivo chegou ao fim, desde o retraimento de seu amor por ele.” (FREUD, 1911/1996, p.77, grifo nosso).
\end{abstract}

Essa afirmação em destaque poderia soar aos nossos ouvidos como uma declaração ingênua de humildade por parte de Freud. Sua angústia de estar sendo influenciado por Abraham foi completamente anulada. Todavia, isso só parece ter sido possível diante da deferência de Abraham para com Freud, deferência essa assumida por Abraham e enfatizada por Freud, na sutil trama de citações entre ambos os textos. Desse modo, se as concepções essenciais formuladas por Freud em seu ensaio sobre Schreber, sobretudo no que tange à economia libidinal das psicoses, já haviam sido esboçadas num trabalho anterior de Abraham, este, por sua vez, revela-se fruto da influência fecunda do próprio Freud em Abraham.

Por um lado, o elogio de Freud a Abraham retorna ao próprio Freud como autopromoção e converte-se em mais capital autoral para si próprio, servindo para reafirmar a primazia de suas idéias (isto é, sua originalidade) frente aos outros psicanalistas da época; por outro, tal elogio, seja a Abraham ou a outros 'discípulos' (como p.ex., Jung e Ferenczi), presenças constantes em seu texto, também são necessárias para que Freud mostre que a psicanálise é científica, isto 
é, ela é um trabalho de pesquisa que pode ser realizado coletivamente — caso a psicanálise se mostrasse uma produção idiossincrática, uma profecia individual, ela se assumiria sem qualquer validade científica. Em outras palavras, Freud tem sempre de equilibrar o reforço de sua autoridade pessoal com o reforço da psicanálise como empreendimento científico, de modo que, quanto mais científica, e portanto coletiva, for a psicanálise, mais ele (Freud) é original porque criou uma ciência, embora, quanto mais original ele for, mais ele reduzirá o caráter científico da psicanálise por fazê-la uma teoria individual. É assim que Freud em seu ensaio sobre Schreber negocia com Abraham: reconhece e reivindica sua voz autoral sobre este autor, ao mesmo tempo que reconhece e confere a Abraham certa originalidade (a primazia na aplicação do saber psicanalítico às psicoses), confirmando com isso a vocação científica da nova disciplina. Pode-se perceber que os vários níveis de negociações em jogo se entrelaçam entre si no texto de Freud sobre Schreber.

Após a citação acima, Freud prepara o terreno para a exposição do grand finale de seu artigo, cuja idéia principal foi declaradamente inspirada em Abraham como se evidenciará na quarta e última referência que fará a este autor. Explica que o recalque na paranóia seria efetuado por meio do desligamento da libido em relação ao mundo, ${ }^{6}$ derivando esta idéia da análise dos delírios escatológicas de Schreber. A libido assim liberada

“(...) vincula-se ao ego e é utilizada para o engrandecimento deste. Faz-se assim um retorno ao estádio do narcisismo (que reconhecemos como estádio do desenvolvimento da libido), no qual o único objetivo sexual de uma pessoa é seu próprio ego. Com base nesta evidência clínica, podemos supor que os paranóicos trouxeram consigo uma fixação no estádio do narcisismo, e podemos asseverar que a extensão do retrocesso do homossexualismo sublimado para o narcisismo constitui medida da quantidade de regressão característica da paranóia." (FREUD, 1911/1996, p.79-80, grifo original).

\section{A quarta referência a Karl Abraham no caso Schreber}

Mais adiante, próximo do final da terceira parte de seu artigo, Freud faz a quarta e última referência a Abraham, só que, desta vez, no próprio corpo do texto: "Abraham muito convincentemente demonstrou que o afastamento da libido do mundo externo é uma característica particular e claramente marcada da demência precoce" (FREUD, 1911/1996, p.83). Em seguida, estabelece o diagnóstico diferencial entre esta doença e a paranóia, afirmando:

\footnotetext{
${ }^{6}$ Como veremos mais adiante, essa seria a descoberta de Abraham mais reconhecida e valorizada por Freud.
} 
“A regressão [no caso da demência precoce] estende-se não simplesmente ao narcisismo (manifestando-se sob a forma de megalomania), mas a um completo abandono do amor objetal e um retorno ao auto-erotismo infantil. A fixação disposicional deve, portanto, achar-se situada mais atrás do que na paranóia, e residir em algum lugar no início do curso do desenvolvimento entre o auto-erotismo e o amor objetal." (FREUD, 1911/1996, p.84)

Consideremos o trecho do artigo de Abraham ao qual Freud provavelmente se refere quando diz que este autor demonstrou de modo convincente que o desligamento da libido do mundo externo é uma peculiaridade da demência precoce:

“A demência precoce conduz, portanto, à supressão do amor objetal e da sublimação. É somente na primeira infância que encontramos tal estado. Para este período [do desenvolvimento psicossexual], denominamos — com Freud — "auto-erotismo", caracterizado pela falta de investimento objetal e de sublimação. A característica psicossexual da demência precoce é a regressão do doente ao auto-erotismo; os sintomas da doença são uma forma de atividade sexual auto-erótica." (ABRAHAM, 1908/1963, p.48, destaque nosso).

Reparemos que neste trecho, Freud é explicitamente citado por Abraham como um autor que, comprovadamente, exerceu influência sobre suas idéias. Sugerimos que Freud recorta no texto de Abraham justamente as passagens que o promovem, reforçando assim sua voz autoral e sua prioridade intelectual, sem contudo deixar de mostrar o caráter compartilhado (e, portanto, científico) da psicanálise.

Essa insistência de Freud em demonstrar uma suposta vocação coletiva da psicanálise parece associada ao fantasma maior que o assombrava: a idéia da psicanálise como mera ilusão. Sugerimos que tal fantasma acompanha Freud desde o início de sua obra psicanalítica e se deve, em parte, à sua ambivalência frente às artes em geral, sobretudo à literatura. ${ }^{7} \mathrm{O}$ assombro freudiano se evi-

\footnotetext{
${ }^{7}$ Sobre as relações ambíguas de Freud com a literatura, ver Mahony (1992). Em síntese: por um lado, Freud via no recurso ao estilo romanesco de escrita, sobretudo de seus casos clínicos (apontado por R. von Krafft-Ebing e H. Ellis), a possibilidade de se comunicar nos domínios da nova disciplina que fundava, para além da linguagem científica meramente descritiva, inócua para os seus propósitos de desvelamento do inconsciente; por outro, é em tom de lamúria resignada e decepção contida que Freud destaca o caráter romanesco e pouco científico de sua narrativa, como nas notas preliminares do caso Dora (1905a/1996, p.20), pois quanto mais íntimo ele se torna da literatura (e do campo artístico em geral), construindo suas teorizações com base em metáforas literárias, mais se afasta de seu programa epistemológico de inspiração positivista de construção de uma ciência psicanalítica.
} 
denciaria em suas Cinco lições de psicanálise (1910/1996), ocasião em que ele declarou experimentar um “devaneio inacreditável”: ao proferir suas lições perante a platéia norte-americana da Universidade de Clarck, a psicanálise deixava de ser um mero produto do delírio (uma produção idiossincrática de um homem só), tornando-se parte valiosa da realidade. Nesse mesmo lastro, Freud encerra seu artigo sobre Schreber afirmando num tom de ironia angustiada: "Compete ao futuro decidir se existe mais delírio em minha teoria do que eu gostaria de admitir, ou se há mais verdade no delírio de Schreber do que outras pessoas estão, por enquanto, preparadas para acreditar” (1911/1996, p.85). Em outras palavras, o futuro decidirá o estatuto de meu texto: ficção literária ou metapsicologia científica? Se levarmos em conta que, em um de seus trabalhos anteriores, Escritores criativos e devaneio, Freud (1908/1996) havia comparado a criação literária com o devaneio (sonho acordado), associando o fazer poético ao brincar infantil, pode-se entender suas preocupações com o aspecto romanesco - e, por extensão, devaneante (fantasioso) — de seus escritos, inconciliável com sua vontade de saber científico.

Nessa rede de negociações complexas, tecida nos primórdios da psicanálise, a centralização da originalidade e da autoridade em torno do nome de Freud, bem como seu recurso estilístico à literatura como modelo de escrita, constituíam os maiores entraves às suas intenções epistemológicas de instituir a psicanálise como uma ciência; por outro lado, a ancoragem do saber psicanalítico em torno da sexualidade e a partilha desse saber com seus discípulos (subordinados) o impulsionavam rumo ao seu intento.

\section{REFERÊNCIAS RECÍPROCAS ENTRE S. FREUD E K. ABRAHAM Abraham em Freud}

Observando o índice de nomes próprios, organizado por James Strachey, da Edição standard brasileira das obras psicológicas completas de Sigmund Freud (v. XXIV), percebe-se que Abraham foi um dos discípulos mais citados por Freud ao longo de sua obra.

Todavia, o reconhecimento de uma dívida teórica de Freud para com Abraham parece limitar-se às contribuições dadas por este autor ao entendimento psicanalítico das psicoses. A mais extensa citação de Freud a Abraham encontra-se na "Conferência XXVI" das Conferências introdutórias sobre psicanálise. Nesse artigo de 1917, Abraham é reconhecido por Freud em seu pioneirismo no entendimento psicanalítico das psicoses:

“(...) Já em 1908, Karl Abraham, após um intercâmbio de idéias comigo, declarou que a principal característica da demência precoce (que se contava entre as psicoses) era que nela a catexia libidinal de objetos estava ausente. No entanto, aí surgiu a questão que consistia em saber o que acontecia à libido nos pacientes com demência precoce, 
retirada dos objetos. Abraham não hesitou em dar a resposta: ela se volta novamente para o ego e esse retorno reflexivo é a fonte da megalomania na demência precoce. A megalomania é, em todos os aspectos, comparável à conhecida supervalorização sexual do objeto na vida erótica [normal]. Desse modo, pela primeira vez chegamos a compreender um traço de uma doença psicótica relacionando-o com a vida erótica normal.

Posso dizer-lhes, de imediato, que essas explicações de Abraham têm sido aceitas na psicanálise e se tornaram a base de nossa atitude relativa às psicoses." (FREUD, 1917a/1996, p.416, sublinhado nosso, grifo original).

Pelo destaque sublinhado, percebe-se que Freud é incapaz de creditar uma originalidade a Abraham sem chamar a atenção do leitor para sua própria influência sobre as idéias do mesmo, que ele enaltece, enaltecendo a si mesmo por tabela. A originalidade, só ao próprio Freud, pai fundador da psicanálise, seria um atributo permitido; aos outros, cabe a posição de colaboradores coadjuvantes na empreitada do mestre de criação de um campo psicanalítico de discussões visando à legitimação científica da psicanálise. Cabe ressaltar que, no segundo parágrafo dessa citação, Freud reforça a relevância de Abraham para o entendimento das psicoses, relevância essa que já havia sido reconhecida seis anos antes pelo próprio Freud a partir da presença (sutil, porém marcante e decisiva) de Abraham no caso Schreber.

\section{Freud em Abraham}

Os textos de Abraham sobre as psicoses que analisamos aqui (1908/1963; 1911/1970a; 1916/1970b; 1924/1970c) estão repletos de referências a Freud. Tais referências chamam a atenção do leitor pela freqüência com que ocorrem e pelo grau de influência sobre suas idéias creditadas a Freud por Abraham. Não pretendemos aqui esgotar a totalidade de tais citações, mas sim empreender um recorte daquelas que ilustram a reverência de Abraham para com Freud.

No artigo Notas sobre as investigações e o tratamento psicanalítico da psicose maníaco-depressiva e estados afins (1911/1970a), após ressaltar a genialidade de Freud em sua revelação da psicogênese da paranóia no caso Schreber, Abraham expõe seu objetivo nos seguintes termos: "Tentarei fornecer aqui uma formulação semelhante [a de Freud sobre a paranóia] da gênese das psicoses depressivas, com base em minhas análises das perturbações mentais depressivas” (idem, p.39). Abraham coloca-se na posição de discípulo que ampliará os conhecimentos produzidos pelo mestre, decifrando transtornos ainda não abordados de forma satisfatória por Freud. ${ }^{8}$

\footnotetext{
${ }^{8}$ Vale ressaltar que o clássico texto freudiano sobre a melancolia (1917b/1996) só seria publicado seis anos mais tarde.
} 
No artigo O primeiro estágio pré-genital da libido (1916/1970b), Abraham assinala, logo no primeiro parágrafo, que Os três ensaios sobre a teoria da sexualidade de Freud, em sua terceira edição revista e ampliada, de 1915, continuava sendo a obra padrão sobre a sexualidade infantil. Propõe-se, então, a tomar essa obra como base teórica de seu artigo, dando-se ao trabalho de resumi-la antes de expor seus argumentos. Após tal resumo, Abraham diz:

“(...) gostaria de apresentar algum material psicopatológico que ficou até aqui quase desconhecido ou, pelo menos, inteiramente desprezado, e que irá demonstrar que a vida instintiva da criança persiste em alguns adultos de uma maneira positiva e inequívoca e que a libido de tais pessoas apresenta um quadro que parece corresponder, em todos os pormenores, à fase oral ou canibalesca estabelecida por Freud.” (1916/1970b, p.55)

Ao que conclui, num tom favorável a Freud: "Os numerosos fatos que reuni nos compelem a aceitar a teoria freudiana de um primitivo estágio canibalesco no desenvolvimento da libido" (ABRAHAM, 1916/1970b, p.80).

No artigo Breve estudo do desenvolvimento da libido, visto à luz das perturbações mentais (1924/1970c), Abraham toma como base teórica de suas idéias o artigo Luto e melancolia de Freud, ressaltando o avanço que esse texto representou com relação às suas “primeiras e incertas tentativas de 1911”. Referindo-se ao material clínico que apresentará nesse artigo (dois casos típicos de psicose maníaco-depressiva cujas análises conduziu), Abraham afirma que

“Os resultados dessas análises confirmaram de maneira surpreendente a concepção de Freud sobre a estrutura das perturbações melancólicas e maníacas. Além disso, apresentam elas um certo número de elementos novos que suplementam a teoria dele em um ou dois aspectos" (1924/1970c, p.83; grifo nosso).

Eis aí o objetivo de Abraham nesse artigo, conforme foi definido pelo próprio autor: suplementar Freud.

Sublinhando as características da prosa de Abraham, Jones afirma que ele

"possuía um sentimento intenso do concreto; mantinha-se preso aos seus dados clínicos [que ilustraram, confirmaram ou expandiram nosso conhecimento da teoria e da prática psicanalíticas (JONES, 1926/1970, p.9)] e nunca condescendia em hipóteses remotas” (ibid., p.8). Nesse sentido, a escrita de Abraham seria o reflexo de sua personalidade, na qual "seria impossível detectar (...) um só traço de ambição pessoal"9 (ibid., p.28).

\footnotetext{
${ }^{9}$ Endossando o ponto de vista de Jones (biógrafo 'oficial' de Freud) acerca de Abraham, que os críticos poderiam objetar ser tendencioso - já que Jones era um dos discípulos de Freud mais atuantes naquela época e, portanto, tinha envolvimento direto nos conflitos
} 
Abraham personificava um bom interlocutor para Freud no campo das psicoses, já que seus textos refletem seu esforço de compilação de material clínico e de confirmação das hipóteses freudianas, reforçando a voz autoral de Freud. O escrúpulo e humildade de Abraham nessas referências permitiram a Freud referir-se a ele no breve obituário que redigiu em sua homenagem como integer vitae scelerisque purus [aquele que é impoluto em vida e puro de culpa] (FREUD, 1926/1996, p.269), conforme o verso original de Horácio.

\section{CONSIDERAÇÕES FINAIS}

O modesto intuito de Abraham enquanto teórico da psicanálise não impediu que seu artigo sobre a demência precoce (1908/1963) ocupasse um lugar privilegiado no ensaio de Freud sobre a paranóia (1911/1996), embora a sutileza e a aparente despretensão das referências a Abraham neste ensaio tenda a fazê-lo passar despercebido às leituras sistemáticas. O artigo de Abraham não se destinou a cumprir o papel de suplemento ao caso Schreber, até porque, cronologicamente, o texto abrahamiano precedeu o de Freud, isto é, as explicações de Abraham da psicogênese da demência precoce, mais tarde enaltecidas por Freud (1917a/1996) como sendo a base do entendimento psicanalítico das psicoses,

emergentes nos primórdios do movimento psicanalítico - , pode-se citar, pelo menos, outros dois biógrafos de Freud contemporâneos. Gay (1989) assinala que os "colegas analistas consideravam-no [a Abraham] calmo, metódico, inteligente, sem se entregar a especulações ou efusões" (p.176, grifo nosso). Breger (2002) nos conta que aqueles que conheceram Abraham descrevem o mesmo leque de qualidades: "otimismo permanente, entusiasmo juvenil, inteligência, segurança, tranqüilidade, serenidade e perseverança”. Comenta, ainda, que Freud teria se impressionado com a lealdade e devoção de Abraham à causa psicanalítica, confiando nele piamente (ibid., p.281). Talvez essa confiança irrestrita de Freud em Abraham adviesse de outro aspecto da personalidade de Abraham que se revelava no interior do movimento psicanalítico: "era um vigilante cão de guarda, sempre alerta para localizar os sinais de desvios”, como na ocasião em que Abraham expulsou Otto Rank da Associação Psicanalítica Internacional, denunciando a suposta regressão científica que teria representado o seu último livro, O trauma do nascimento, de 1924 (ibid., p.282). Acerca dos seus escritos, Breger destaca que "Abraham sempre começava com uma homenagem ao Fundador e só então desenvolvia algum aspecto da obra de Freud. Jamais questionava os pressupostos da teoria, nem a autoridade do mestre, nem aquilo que a "psicanálise conhece”" (ibid., p.282-283, grifo nosso). Uma breve análise psicocrítica de Abraham e de suas relações com Freud foi realizada por Mezan (1999), autor esse que circunscreveu um traço característico de Abraham: o de baluarte da ortodoxia. Era um homem extremamente inteligente sem ser contestatório. Parece que ele teria encontrado na pessoa de Freud e no movimento psicanalítico um substituto paterno não ameaçador. Sobre as correspondências entre Freud e Abraham (FREUD \& ABRAHAM, 2001), Mezan (idem) destaca que, diferentemente dos outros discípulos, a postura clara de Abraham é sempre a de não contestar: nem os fundamentos teóricos da psicanálise, nem a posição paterna, de liderança, que cabia a Freud. Cabe ressaltar que optamos por seguir o artigo de Jones (1926/1970) ao longo deste trabalho por se tratar da base de todo relato biográfico de Abraham desde então, cujos escritos mais recentes, acima citados, vêm endossar. 
precederam e embasaram as próprias hipóteses freudianas acerca da psicogênese da paranóia.

Diante do texto de Abraham, Freud lembrou-nos Pierre Menard - personagem de Borges (2001) — perante o Dom Quixote, de Cervantes. De modo semelhante a Menard, que, encarnando Cervantes, se apossou deliberadamente de partes da novela cavaleiresca como se tivessem sido escritas por ele próprio, 'reescrevendo-as' sem mudar uma única vírgula da versão original, Freud reivindica sua propriedade intelectual sobre o texto de Abraham, (re) escrevendo a história da psicanálise das psicoses a partir do caso Schreber. Talvez essa proposição se clarifique mais se tomarmos a afirmação chistosa de Freud a Abraham, numa carta que lhe endereçou em 18 de dezembro de 1910, ocasião na qual acabara de redigir seu ensaio clínico: "Naturalmente, tengo que plagiarle ampliamente en este trabajo [sobre Schreber]” (FREUD \& ABRAHAM, 2001, p.130).

O leitor familiarizado com os Três ensaios sobre a teoria da sexualidade (FREUD, 1905b/1996) que ler o artigo de Abraham sobre a psicologia da demência precoce (1908/1963) pode, não sem razão, objetar que exageramos a importância que este artigo teve sobre o caso Schreber de Freud, até porque Abraham, como vimos, assumiu em seu texto a influência capital de Freud sobre suas idéias; além disso, a teoria da sexualidade de Freud norteia o texto abrahamiano sobre a demência precoce de fora a fora, passando-nos uma impressão incontida de déjà-vu.

De fato, o artigo de Abraham sobre a psicologia da demência precoce não ampliou nem alterou as hipóteses freudianas fundamentais sobre a teoria da sexualidade - tal era a marca registrada de seus escritos, assinalada por Jones (1926/1970), Gay (1989) e Breger (2002). Todavia, a novidade que Abraham traz nesse artigo de 1908 é a aplicação dessa teoria à demência precoce (ou à 'esquizofrenia', como Bleuler depois a batizaria), lançando luz sobre uma categoria nosológica ainda não estudada por Freud, cujas hipóteses, depois de serem desenvolvidas no caso Schreber, tornar-se-iam a base do entendimento psicanalítico das psicoses.

O objetivo central de Abraham nesse artigo foi provar que a psicanálise poderia explicar a demência precoce; nesse sentido, seu artigo é uma defesa aberta de Freud contra Jung, que era cético com relação à aplicação da psicanálise às psicoses. Abraham argumentava que as perturbações do ego pudessem ser puramente secundárias às perturbações da libido (contrariamente ao que propunha Jung), sendo assim possível aplicar a teoria da sexualidade freudiana à elucidação da demência precoce. A demência precoce surgiria, segundo Abraham, da incapacidade de investimento objetal e de sublimação. A retirada da libido dos objetos e sua convergência ao eu seria a fonte da megalomania e dos delírios persecutórios na demência precoce, cuja peculiaridade psicossexual residiria 
num desenvolvimento inibido no nível auto-erótico, com uma conseqüente tendência a regredir a esse nível.

Abraham foi pioneiro entre os psicanalistas e sua fidelidade e deferência para com as idéias freudianas, somada à sua primazia na aplicação dessas idéias às psicoses, abririam caminho ao caso clínico de Freud sobre a paranóia. Um dos aspectos mais interessantes dessa relação entre Freud e Abraham é a impossibilidade de se atribuir uma originalidade exclusiva a tal ou qual autor. O primeiro encontro entre Freud e Abraham ocorreu em Viena, em 1907. Abraham havia acabado de se exonerar do cargo em Burghölzli e estava ávido por um estreitamento dos laços com Freud, de quem era um admirador confesso. Jones assinala que o artigo de Abraham sobre a psicologia da demência precoce teria sido fruto desse fecundo primeiro encontro entre ambos (1926/1970, p.4). Especulemos que Freud tenha, naquela ocasião, delegado a Abraham - então jovem psiquiatra com larga experiência institucional (tendo em vista a autoridade científica que Burghölzli lhe conferia) - a atribuição de se aventurar no campo da psicanálise das psicoses, e que Abraham tenha correspondido às expectativas de Freud redigindo seu artigo de 1908. Por considerar sua experiência privada de consultório insuficiente para conclusões no campo das psicoses, Freud teria buscado em Abraham o aval (a ancoragem científica) de um psiquiatra asilar às suas idéias. E mesmo que essa hipótese esteja correta, isto é, mesmo que Freud tenha, de fato, delegado a Abraham a tarefa de teorizar sobre as psicoses, isso não o livrou da cobrança posterior da dívida, diante de sua necessidade inelutável de afirmar sua primazia intelectual sobre Abraham no caso Schreber.

Levando-se em consideração o contexto histórico no qual o caso Schreber foi redigido, a preocupação de Freud com sua originalidade nesse ensaio manifestar-se-ia como uma defesa contra a força performativa dos enunciados de seus discípulos dissidentes (a criação das escolas adleriana e junguiana de psicanálise viriam atestar tal força) num momento de acirrada contestação dos conceitos fundamentais da psicanálise.

Nesse sentido, a presença marcante de Abraham no caso Schreber de Freud pode ter sido sobredeterminada pela própria postura de Abraham frente tais disputas teóricas. Diante de um mar revolto de críticas e contestações à psicanálise, Abraham teria representado um porto seguro para Freud. Vale ressaltar que Abraham manteve-se fiel a Freud durante toda a vida — interrompida abruptamente em 1925 com sua morte prematura, quando contava 48 anos de idade. Jones nos conta que, desde o início da dissidência de Jung com Freud, Abraham tomou o partido do mestre, tendo inclusive liderado a oposição contra Jung a partir do Congresso Psicanalítico de Munique, em 1910 (1926/1970, p.4-6). Em A história do movimento psicanalítico, Freud reconheceu publicamente a lealdade de Abraham na postura crítica que este adotou perante Jung (1914/1996, p.67). Ao 
passo que, no breve obituário de Abraham que Freud redigiu, afirmou: “Dentre todos aqueles que me acompanhavam pelos sombrios caminhos da pesquisa psicanalítica, ele [Abraham] granjeou um lugar tão proeminente que somente um outro nome [Ferenczi] poderia ser posto ao lado dele” (1926/1996, p.269).

No caso Schreber, Freud atualizou todo o conhecimento psicanalítico construído até então, que tinha como pilar sua teoria sexual da libido, mostrando que essa teoria era capaz de explicar a paranóia. Ora, em seu artigo de 1908, Abraham, tendo recebido a declarada influência de Freud, não havia demonstrado que a teoria da sexualidade freudiana explicava a demência precoce? Assim, Freud teria vislumbrado em Abraham a antecipação do seu projeto de apropriação teórica das psicoses por intermédio de sua teoria da sexualidade. Abraham antecipava as hipóteses que Freud desenvolveria no caso Schreber, daí a sólida presença daquele autor nesse caso clínico. Abraham representava a unidade da teoria sexual da libido (e, portanto, do saber psicanalítico), contra a fragmentação da mesma, que começava a ser proposta por Jung. Porém, citar Abraham e, por conseguinte, validar sua teoria da sexualidade no campo das psicoses, legitimando-a por intermédio do capital simbólico de Burghölzli, não se dava sem uma dose de angústia por parte de Freud, a qual ele tratou de aplacar destacando sua primazia intelectual sobre Abraham.

Recebido em 6/2/2007. Aprovado em 15/6/2007.

\section{REFERÊNCIAS}

ABRAHAM, K. (1908/1963) “Les différence psychosexuelles entre l'hystérie et la démence precoce", in Oeuvres completes — Tome I. Paris: Payot.

(1911/1970a) "Notas sobre as investigações e o tratamento psicanalítico da psicose maníaco-depressiva e estados afins”, in Teoria psicanalítica da libido. Rio de Janeiro: Imago.

(1916/1970b) “O primeiro estágio pré-genital da libido”, in Teoria psicanalítica da libido. Rio de Janeiro: Imago.

(1924/1970c) "Breve estudo do desenvolvimento da libido, visto à luz das perturbações mentais”, in Teoria psicanalítica da libido. Rio de Janeiro: Imago.

BORGES, J. L. (2001) “Pierre Menard, autor do Quixote”, in Ficções. São Paulo: Globo.

BRANNIGAN, J. (1998) New historicism and cultural materialism. New York:

St. Martin's Press.

BREGER, L. (2002) Freud: o lado oculto do visionário. Barueri(SP): Manole.

FIGUEIREDO, L. C. (1999) Palavras cruzadas entre Freud e Ferenczi. São Paulo: Escuta. 
FREUD, S. (1996) Edição standard brasileira das obras psicológicas completas de Sigmund Freud. Rio de Janeiro: Imago.

(1905a) "Fragmento da análise de um caso de histeria”, v.VII, p.15-116.

(1905b) “Os três ensaios sobre a teoria da sexualidade", v.VII, p.119-229.

(1908) “Escritores criativos e devaneio”, v.IX, p.133-143.

(1910) “Cinco lições de psicanálise”, v.XI, p.17-65.

(1911) “Notas psicanalíticas sobre um relato autobiográfico de um caso de paranóia (dementia paranoides)", v.XII, p.15-89.

(1914) “A história do movimento psicanalítico”, v.XIV, p.15-89.

(1917a) "Conferência XXVI: A teoria da libido e o narcisismo. Conferências introdutórias sobre psicanálise”, v.XVI, p.413-431.

(1917b) “Luto e melancolia”, v.XIV, p.15-89.

(1926) “Breves escritos: Karl Abraham”, v.XX, p.269.

. \& ABRAHAM, K. (2001) Correspondencia completa 1907-1926. Madrid: Síntesis.

GALLAGHER, C. \& GREENBLATT, S. (2000) A prática do novo historicismo. Bauru: Edusc.

GAY, P. (1989) Freud: uma vida para o nosso tempo. São Paulo: Companhia das Letras.

GREENBLATT, S. J. (1991) O novo historicismo: ressonância e encantamento. Estudos históricos, v.4, n.8. Rio de Janeiro: Fundação Getúlio Vargas, p.244-261.

JONES, E. (1970) “Introdução”, in ABRAHAM, K. Teoria psicanalítica da libido. Rio de Janeiro: Imago.

LOTHANE, Z. (1992) In Defense of Schreber: Soul Murder and Psychiatry. New Jersey: Analytic Press.

MAHONY, P. (1992) Freud como escritor. Rio de Janeiro: Imago.

MEZAN, R. (1999) O inconsciente segundo Karl Abraham. Revista Psicologia USP, v.10, n.1. São Paulo: Edusp, p.55-95.

SANTNER, E. (1997) A Alemanha de Schreber: uma história secreta da modernidade. Rio de Janeiro: Jorge Zahar.

Rogério Paes Henriques

rsphenriques@oi.com.br 